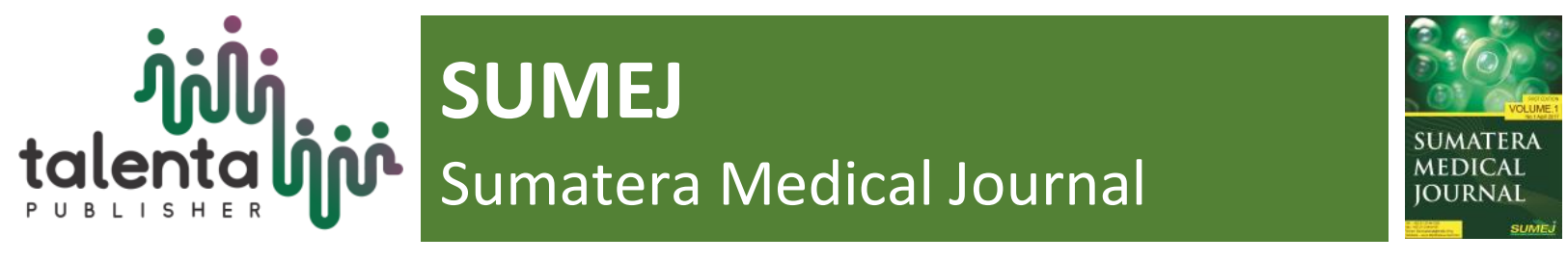

\title{
Relationship Between CHA2DS2-VASC Score With CIN For AMI Patients After PCI
}

\author{
H.W. Parlindungan, N.Z. Akbar, A.N. Nasution, H. Hasan, A.C. Lubis, \\ B.G. Napitupulu
}

Department of Cardiology and Vascular, Faculty of Medicine, Universitas Sumatera Utara, North Sumatera, Medan, Indonesia

\begin{abstract}
The CHA2DS2-VASC score has been reported recently to predict adverse clinical outcomes so is CIN in patients with AMI regardless of having AF. We investigated relationship between CHA2DS2-VASC score with CIN in patients who underwent PCI strategies. This is a study of 40 patients with and underwent PCI. The CHA2DS2-VASC score was calculated for each patient. From this study 16 cases(18.82\%) of CIN were diagnosed. CIN was defined as rise in serum creatinine $>0,5 \mathrm{mg} / \mathrm{dL}$ or $>25 \%$ increase in baseline within $24 \mathrm{~h}$ after PCI. In the ROC curve analysis, the cut-off value of CHA2DS2VASC score in the prediction of CIN was $>4$ (sensitivity:56.25\%,Specificity:87.5\%)(AUC0.698,95\%:CI1.460-6.163,p=0.003) and has a significant association with $\mathrm{CIN}(\mathrm{R} 20.485)$. We also identified $\mathrm{Hb}$ level $<12 \mathrm{mg} / \mathrm{dL}$ as an independent predictor of CIN with (RR3.44,95\%:CI1.816-6.532,p<0.001). The CHA2DS2-VASC score was positively associated with CIN. Therefore, it can be used as a simple and reliable tools to predict CIN in AMI patients who underwent PCI.
\end{abstract}

Keyword: CHA2DS2-VASC,CIN,PCI,AMI

Received 02 September 2019 | Revised 11 September 2019 | Accepted 17 Oktober 2019

\footnotetext{
*Corresponding author at: Department of Cardiology and Vascular, Faculty of Medicine, Universitas Sumatera Utara

E-mail address: hwpsinurat19@gmail.com
} 


\section{$1 \quad$ Introduction}

Cardiovascular disease (CVD) is a leading cause of death worldwide (WHO, 2014). Renal injury as one of its adverse outcome is increasingly being seen in patients with acute myocardial infarction (AMI). As well as renal impairment can also be found due to the use of contrast agent in the setting of AMI patients who underwent percutaneous coronary intervention (PCI) known as Contrast Induced Nephropathy (CIN) (Gleeson, 2004).

Some study recently described the components of CHA2DS2-VASC score such as older age, hypertension, diabetes mellitus, heart failure, and female as a novel predictor of severity and also adverse outcomes in cardiovascular disease including CIN, despite of having atrial fibrillation (Kurtul, 2017; Marenzi, 2004). Thus, we aimed to investigate thepredictive value of CHA2DS2VASC score as a simple toolfor CIN in patients with ACS who underwent PCI.

\section{Methodology}

This was a single center study in which a total of 40 consecutive acute coronary syndrome (ACS) patients from total 84 patients ACS who underwent PCI at our hospital. The exclusion criteria was patients with hypotension state during PCI or using any inotropic for stabilizing haemodynamic, shock cardiogenic, atrial fibrillation, and patients with post cardiac resuscitation.

Clinical and demographic characteristicswere obtained bymedical history, physical examination, electrocardiographicfindings, echocardiographic examination, and laboratory data. The CHA2DS2-VASC score was calculated foreach patientwith the lowest score was 1 and the highest score was 9, because all of the patients consider have vascular disease due to AMI.The study was approved bythe local ethics committee, and all patients provided theirwritten informed consent (Kurtul, 2017).

Baseline serum creatinine was determined atadmission, and serum creatinine measurement was repeated 24 after PCI. The eGFR was calculatedusing the Cockroft-Gault formulaand using the serum creatinine measured at admission.Routine hemogram parameters, fasting lipid profiles, fasting glucose, 2 hours post prandial glucose, $\mathrm{HbA} 1 \mathrm{C}$, and serum electrolytes were alsomeasured. CIN was defined as the elevation of serumcreatinine $0.5 \mathrm{mg} / \mathrm{dl}$ or $25 \%$ in baseline serum creatininewithin 24 hours after PCI (McCullough, 2008).

All statistical analyses were performed using statistical software, and a $\mathrm{p}$ value $<0.05$ was considered significant. Receiver operatingcharacteristic curve analysis was used to determine the optimumcut-off valuesof CHA2DS2-VASC score to predictthe development of CIN. Data were comparedwith the use of Student $t$ or ManneWhitney $U$ test forcontinuous variables (expressed as meanstandarddeviation for parametric variables and median and interquartileranges [ 25 to 75 percentile levels] for nonparametricvariables) and the chi-square or Fisher's exact test for categoricalvariables (expressed as counts and percentages). Continuous variables were analyzed for normal distributionusing the KolmogorovSmirnov test. To address concernsover confounding 
variables affecting CIN development, wealso performed a multivariate logistic regression analysis.Variables significantly associated with CIN, but notincluded in the calculation of the CHA2DS2-VASC score, were entered into the multivariate model.

\section{Results}

From total of 85 ACS patients who were admited to our cardiac care unit, 40 patient were enrolled to our study, and 16 patients were diagnosed with CIN (18.82\%). The mean age of our study population was $54.28 \pm 8.121$ years, and the mean CHA2DS2-VASC score was $1.82 \pm 1.152$.

On bivariate analysis, CHA2DS2-VASC score $\geq 4$ (relative risk [RR] 3, 95\%CI 1.460-6.163; $\mathrm{p}=0.003$ ), Hb level < 12mg/dL (relative risk [RR] 3.44, 95\%CI 1.816-6.532; $\mathrm{p}<0.001$ ), eritrosit level (relative risk [RR] 2.778, 95\% CI 1.268-6.084; $\mathrm{p}=0.008$ ), hematokrit level (relative risk [RR] 4.09, 95\%CI 1.582-10.412; p<0.001), HDL level (relative risk [RR] 1.8, 95\%CI 0.766-4.229; $\mathrm{p}=0.154$ ), and Mehran score (relative risk [RR] 0.491, 95\%CI 0.221-1.090; $\mathrm{p=0.069)}$ (Table 2)

From multivariate analysis CHA2DS2-VASC score $\geq 4$ and $\mathrm{Hb}$ level $<12 \mathrm{mg} / \mathrm{dL}$ wereindependent predictors for CIN after urgent PCI in patientswith ACS ( $\left.\mathrm{R}_{2} 0.485\right)$ (Table 4).

\section{Discussion}

The present study demonstrated that the CHA2DS2-VASC score $\geq 4$ was independently associated with CINdevelopment in patients with ACS who were treated byurgent PCI.CIN, an important complication after PCI, especially inthe setting of ACS, is associated with extended length ofhospital stays, increased costs, and increasedshortandlong-term morbidity and mortality.Althoughpathophysiological mechanisms of CIN is not fullyunderstood, researchers concluded that CIN is caused byrenal vasoconstriction, endothelial dysfunction, endotheliumcell damage, followed by renal tubular injury and medullaryhypoxia (Mehran, 2006). From previous study advanced age, female gender, diabetes mellitus, $\mathrm{CHF}$, and renal dysfunctionare already wellknownrisk factors for CIN.The components of the CHA2DS2-VASC score include similar risk factors for CIN so there are opinion arise that CHA2DS2-VASC score can also predict the CIN event. From multivariate analysis in this study we conclude that CHA2DS2-VASC score was an independent risk factor for CIN regardless having AF. 


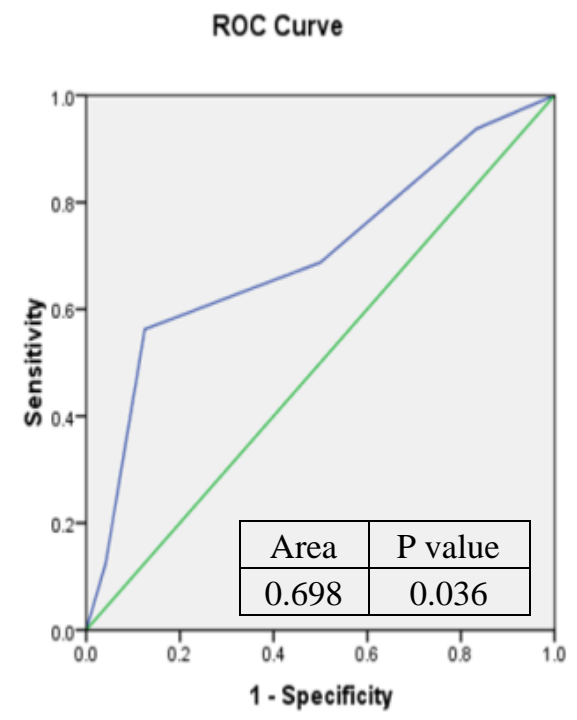

Figure 1. ROC Curve Analysis for The Presenceand Number of CHA2DS2-VASC Scores for Predicting Contrast-Inducednephropathy.

Table 1. Significancy Value of CHA2DS2-VASC Score

\begin{tabular}{ccc}
\hline $\begin{array}{c}\text { Positive if Greater } \\
\text { Than or Equal To }\end{array}$ & Sensitivity & 1-Specificity \\
\hline .00 & 1.000 & 1.000 \\
1.50 & .938 & .833 \\
2.50 & .688 & .500 \\
3.50 & .562 & .083 \\
4.50 & .125 & .042 \\
6.00 & .000 & .000 \\
\hline
\end{tabular}

Table 2. Bivariate Analysis of Independent Predictors Of CIN

\begin{tabular}{|c|c|c|c|c|c|}
\hline \multirow{2}{*}{ Variable } & \multirow{2}{*}{$95 \% \mathrm{CI}$} & \multirow{2}{*}{ RR } & \multicolumn{2}{|c|}{ CIN } & \multirow{2}{*}{$\mathrm{p}$-value } \\
\hline & & & Yes & No & \\
\hline$<74$ & $1.13-17.07$ & 2.42 & 11 & 8 & 0.051 \\
\hline$\geq 74$ & & & 5 & 16 & \\
\hline$<12$ & $1.816-6.532$ & 3.44 & 8 & 1 & $<0.001$ \\
\hline$\geq 12$ & & & 8 & 23 & \\
\hline$<4.5$ & $1.268-6.084$ & 2.778 & 10 & 5 & 0.008 \\
\hline$\geq 4.5$ & & & 6 & 19 & \\
\hline$<39$ & $1.582-10.412$ & 4.09 & 12 & 5 & 0.001 \\
\hline$\geq 39$ & & & 4 & 19 & \\
\hline Mehran $<9$ & $0.221-1.090$ & 0.491 & 6 & 10 & 0.069 \\
\hline$\geq 9$ & & & 16 & 8 & \\
\hline \multicolumn{6}{|l|}{ CHA2DS2-VASc } \\
\hline$<4$ & $1.460-6.163$ & 3 & 9 & 3 & 0.003 \\
\hline$\geq 4$ & & & 7 & 21 & \\
\hline $\mathrm{HDL}>40$ & $0.766-4.229$ & 1.80 & 5 & 13 & 0.154 \\
\hline$<40$ & & & 11 & 11 & \\
\hline
\end{tabular}


$\overline{\text { Recently,Kurtul et alhave concluded a CHA2DS2-VASC score of } \geq 4 \text { is an independent }}$ predictor for incidence. There is no difference of cut off point despite small sample size in our study and differences of patients characteristic in our study.Also, we compare the association in predicting CIN with Mehran score. In bivariate and multivariate analysis, the CHA2DS2-VASC score has more association in predicting CIN than Mehran score, but this finding must be tested in larger sample.

Tabel 3. Multivariate Model Analysis of Independent Factors of CIN

\begin{tabular}{cccc}
\hline Step & $\begin{array}{c}-2 \text { Log } \\
\text { likelihood }\end{array}$ & $\begin{array}{c}\text { Cox \& Snell } \\
\text { R Square }\end{array}$ & $\begin{array}{c}\text { Nagelkerke } \\
\text { R Square }\end{array}$ \\
\hline 1 & $30.592 \mathrm{a}$ & .441 & .596 \\
2 & $32.898 \mathrm{~b}$ & .408 & .551 \\
3 & $34.104 \mathrm{~b}$ & .389 & .527 \\
4 & $36.086 \mathrm{~b}$ & .358 & .485 \\
\hline
\end{tabular}

From this study we found that dyslipidemia, smoker, and family history as risk factor of CAD has significant value in CIN (+) group. The combined oxidative stress, inflammation and dyslipidemiacan accelerate atherosclerosis, the basic pathophysiology of all kinds of vascular disease (Park, 2016).

The present study had some limitations. First, the presentstudy was a single-center study and has small sample. Second, we don't fully assessed the kind of contrast media as confounders of CIN. Finally, we also don't predict others adverse outcome such MACE in our study.

\section{Conclusion}

From this study we can conclude CHA2DS2-VASC score can be used as a simple, more reliable tool topredict CIN in patients who underwent PCI.

\begin{tabular}{lccc}
\hline \multicolumn{1}{c}{ Characteristic } & \multicolumn{2}{c}{ CIN Event } & \\
& $\begin{array}{c}\text { CIN (+) } \\
(\mathrm{n}=16)\end{array}$ & $\begin{array}{c}\text { CIN }(-) \\
(\mathrm{n}=24)\end{array}$ & P value \\
\hline Age (years) & $53.12 \pm 9.062$ & $55.04 \pm 7.532$ & 0.472 \\
Sex Category (n,\%) & & & \\
$\quad$ Male & $12(30 \%)$ & $19(47.5 \%)$ & 0.757 \\
$\quad$ Female & $4(10 \%)$ & $5(12.5 \%)$ & \\
Diabetes Mellitus (n,\%) & $8(20 \%)$ & $8(20 \%)$ & 0.292 \\
Hipertension (n,\%) & $11(27.5 \%)$ & $14(35 \%)$ & 0.505 \\
Dislipidemia (n,\%) & $12(30 \%)$ & $8(20 \%)$ & 0.010 \\
Smoker(n,\%) & $11(27.5 \%)$ & $8(20 \%)$ & 0.028 \\
Family History (n, \%) & $12(30 \%)$ & $6(15 \%)$ & 0.002 \\
CHF (n,\%) & $10(25 \%)$ & $8(20 \%)$ & 0.069 \\
Stroke (n,\%) & $1(2.5 \%)$ & $0(0 \%)$ & 0.215 \\
Vascular Disease (n, \%) & $1(2.5 \%)$ & $0(0 \%)$ & 0.215 \\
Laboratorium & & & \\
$\quad$ Hb & $12.1562 \pm 1.95345$ & $14.3500 \pm 1.29581$ & $<0.001$ \\
Hematokrit & $35.75 \pm 5.615$ & $43.29 \pm 4.486$ & $<0.001$ \\
Ureum pre PCI & $46.38 \pm 49.679$ & $35.29 \pm 17.652$ & 0.320 \\
Creatinin pre PCI & $1.3706 \pm 1.16101$ & $.9958 \pm .38528$ & 0.149 \\
CrCl & $84.0000 \pm 44.88058$ & $88.1667 \pm 30.02414$ & 0.726
\end{tabular}




\begin{tabular}{lccc}
\hline Ureum post PCI & $64.50 \pm 51.024$ & $35.21 \pm 16.59$ & 0.012 \\
Creatinin post PCI & $2.8131 \pm 3.67862$ & $.9287 \pm .24503$ & 0.016 \\
HDL & $33.00 \pm 10.614$ & $41.54 \pm 11.595$ & 0.024 \\
\hline
\end{tabular}

Table 3. Baseline Characteristic

\section{REFERENCES}

[1] Gleeson TG, Bulugahapitiya S. Contrast-induced nephropathy. Am J Roentgenol. 2004;183:1673-89.

[2] Kurtul A, Yarlioglues M, Duran M. Predictive value of CHA2DS2-VASC score for contrast induced nephropathy after percutaneus coronary intervention for acute coronary syndrome. Am J Cardiol. 2017;119:819-825.

[3] Marenzi G, Lauri G, Assanelli E, et al. Contrast-induced nephropathy in patients undergoing primary angioplasty for acute myocardial infarction. J Am Coll Cardiol. 2004;44:1780-5.

[4] McCullough PA. Contrast-induced acute kidney injury. J Am Coll Cardiol. 2008;51:14191428.

[5] Mehran R, Nikolsky E. Contrast-induced nephropathy: Definition, epidemiology, and patients at risk. Kidney Int Suppl. 2006;100:11-15.

[6] Park HS, Kim CS, Hwang BH, Kim TH, Koh YS, Park HJ, et al. HDL Cholesterol Level Is Associatedwith Contrast Induced Acute KidneyInjury in Chronic Kidney DiseasePatients Undergoing PCI. Scientific Reports. 2016.6:35774.

[7] World Health Organization. Global Health Estimates: Deaths by cause, age, sex, and country, 2000-2012. Geneva: WHO. 2014. 